\title{
Classroom Analysis of a Packed Bed Reactor with and without the Use of Effectiveness Factor
}

\author{
Sebastiao R. Ferreira \\ Department of Chemical Engineering, University Federal of Rio Grande do Norte, Natal, Brazil \\ Email: Ferreira@eq.ufrn.br, seba@ufrnet.br
}

How to cite this paper: Ferreira, S. R. (2016). Classroom Analysis of a Packed Bed Reactor with and without the Use of Effectiveness Factor. Creative Education, 7, 20942106.

http://dx.doi.org/10.4236/ce.2016.715209

Received: July 29, 2016

Accepted: September 10, 2016

Published: September 13, 2016

Copyright $\odot 2016$ by authors and Scientific Research Publishing Inc. This work is licensed under the Creative Commons Attribution International License (CC BY 4.0).

http://creativecommons.org/licenses/by/4.0/

\begin{abstract}
Classroom analysis of a packed bed reactor with and without the use of effectiveness factor $(\eta)$ is discussed in this article. The use of $(\eta)$ in the calculation of an isothermal packed bed reactor with convection and first-order reaction rate is analyzed. An analytical model has been developed with and without $(\eta)$. The model without $(\eta)$ was presented in a 50-min lecture and later used in a 50-min computational laboratory session with various groups of two students to calculate the length and catalyst mass in a packed bed reactor. In another class, the students calculated the model using $(\eta)$. Four or five class activities were tested every month in pairs of students in the place of traditional exams. A questionnaire was prepared to verify the students' level of difficulty in understanding two theoretical topics taught in the last two classes, difficulty in doing the requested calculations, as well as among calculations using the effectiveness factor and without it. We have included a question in the questionnaire on how the students felt about the elimination of one traditional monthly exam in Chemical Reactor Design. In the two semesters when the questionnaire was applied to the Chemical Reactor Design class, on average, $86 \%$ of the students preferred various class group activities as opposed to traditional exams, $80 \%$ of the students reported that they had little difficulty in understanding the two theoretical sections in the last two classes, $57 \%$ stated that they did not have any difficulty in doing the requested calculations and 51\% reported that the calculation methods with the use of $(\eta)$ and without its use were somewhat similar.
\end{abstract}

\section{Keywords}

Classroom Teaching, Effectiveness Factor, Chemical Reactor Engineering

\section{Introduction}

Chemical reaction engineering is one of the most important courses in chemical engi- 
neering programs and addresses many concepts that are applicable in various areas (Mahecha-Botero, Reaume, Grace, \& Ellis, 2011). Computer-aided design has become extremely popular, and its use in classes may be very helpful by adding to the analysis capacity in all engineering areas (Cartaxo, Silvino, \& Fernandes, 2014).

Academic laboratories have traditionally been used to complement and reinforce theoretical instruction that is conveyed through lectures in a practical way. However, data processing and model evaluation tasks are time consuming and do not add much to students' learning experiences because they reduce the time that is available for result analysis, critical thinking and report writing skill development (Stammitti, 2013). Stammitti (2013) selected three Transport Phenomena Laboratory experiments, namely metallic bar temperature profiles, transient heat conduction and fixed and fluidized bed performance, and developed a spreadsheet for each one. These spreadsheets comprise analytical and numerical solutions of different models, as well as correlations available in the literature. Fifteen chemical engineering students who tested the spreadsheets were surveyed, showing that spreadsheets were considered useful for reducing workload and boosting the quality of the analyses because students had the new possibility of quickly practicing with diverse correlations and models (Stammitti, 2013).

According to Glassey, Novakovic, \& Parr (2013), traditional curriculum delivery in higher education has long been considered ineffective in promoting deep learning. Enquiry Based Learning (EBL) provides an opportunity to develop important professional attributes within subject-specific content. Computer-aided learning packages can be a useful tool in supporting the development of these skills because they enable students to explore and gain experience in new software environments in a subject-specific context. Glassey, Novakovic, \& Parr (2013) developed and delivered case studies in Stages 1 and 2 of a chemical engineering degree program by utilizing a number of different software packages. The Stage 2 case studies concentrate on separation processes and the reactor engineering aspect while requiring application of the knowledge of statistics and design of experiments, respectively. A turning point questionnaire was administered to Stage 2 students $(n=66)$ following the completion of the case study containing seven questions about the effectiveness of the case study and students' perceptions of its impact. Anonymous comments and additional suggestions were also collected as free-text comments (Glassey, Novakovic, \& Parr, 2013).

According to Regalado-Méndez, Cid-Rodríguez, \& Báez-González (2010), their work is focused on a project that integrates curriculum such as thermodynamics, chemical reactor engineering, linear algebra, differential equations and computer programming. The purpose is for students to implement most of their knowledge and tools to analyze a stirred tank chemical reactor as a simple dynamic system. The students showed a bigger interest in this practice because they worked in groups. The most important fact is that the percentage of failure among students was $10 \%$ (Regalado-Méndez, Cid-Rodríguez, \& Báez-González, 2010).

Dahm \& Hesketh (2008) describe two chemical reaction experiments developed for Rowan University's introductory course on chemical reaction engineering, i.e., an este- 
rification reaction carried out in a packed bed and a competitive reaction in which the kinetics were influenced by micromixing. Dahm \& Hesketh's (2008) paper describes the use of the experiments in the classroom and compares the performance of the 2005 students to the 2004 cohort for whom the course included no wet labs at all.

According to Luzi, Bressa, Mazza, \& Barreto (2014), many undergraduate chemical engineering curricula do not include non-catalytic or homogeneously catalyzed GasLiquid Reactions (GLRs) and heterogeneous catalysis. Available textbooks dealing with GLRs describe and separately formulate the different processes affecting the rate of chemical absorption. From the analogy with the effectiveness factor concept $(\eta)$, a liquid utilization factor is defined in gas-liquid reactions (Froment, Bischoff, \& Wilde, 2011: p. 329). The Hatta number is very similar to the Thiele modulus used in the $(\eta)$ (Froment, Bischoff, \& Wilde, 2011: p. 328) approach of the present article. This dimensionless group provides a convenient measure of the promoting effect of a chemical reaction on the rate of absorption (Bird, Stewart, \& Lightfoot, 2002: p. 696). There are several similarities between the gas-liquid reaction modeling presented by Luzi, Bressa, Mazza, \& Barreto (2014) and the subject covered in this article.

In the course on chemical reactor design in the Chemical Engineering Department of the Federal University of the Rio Grande do Norte, Brazil, the laboratory modules are carried out concomitantly with or in parallel to theoretical classes. Subsequent to the lectures, topics such as Chemical Reactor Design basic equations are developed on Excel spreadsheets and Fortran programs for the numerical simulation of reactors. The overall quality of the resulting student work is very good, and the students generally do not struggle to discuss their experimental investigation results (Ganley, 2015).

Three years ago we began to teach the Chemical Reactor Design discipline, we were basing the teaching of the Chemical Reactors design discipline on our 15-year experience in the teaching of Transport Phenomena. The traditional monthly exams were replaced with class activities. The activities were performed in pairs using Excel spreadsheets and were developed and employed in Fortran simulation programs.

The students were able to develop spreadsheets for calculations in Sections 2 and 3 of the present article. Details on the important concepts are considered as a prerequisite at this point and are taught in the mass transfer course at our university. Nevertheless, the chemical reactor design lecturer discussed the effectiveness factor $(\eta)$ concept to facilitate the students' task.

In 1939, Thiele introduced the concept of an internal effectiveness factor $\left(\eta_{\text {internal }}\right)$ in the well-known paper titled, "Relation between catalytic activity and size of particle" (Thiele, 1939). The $\left(\eta_{\text {internal }}\right)$ was defined as being the rate of the reaction with pore diffusion resistance divided by the rate of the reaction on surface conditions $R_{A(\text { surf }}\left[\mathrm{kg} \cdot \mathrm{mol} /\left(\mathrm{m}^{3} \cdot \mathrm{s}\right)\right]$ in all catalyst particle active sites (Froment, Bischoff, \& Wilde, 2011: p. 194). The observed reaction rate $R_{A(\mathrm{obs})}$ in a particle can be expressed by $R_{A(\text { surf })}$ multiplied by $\left(\eta_{\text {internal }}\right)$.

The overall effectiveness factor $\left(\eta_{\text {overall }}\right)$ is defined as being the actual $R_{A(\mathrm{obs})}$ divided by the rate $R_{A(\text { reference) }}$ that would result if the entire surface of all the active sites of the catalyst particle was exposed to the bulk concentration. The $R_{A(\mathrm{obs})}$ in a particle can be ex- 
pressed by $R_{A(\text { ref })}$ multiplied by $\left(\eta_{\text {overall }}\right)$. Various authors (Bird, Stewart, \& Lightfoot, 2002; Fogler, 1992, 2006; Froment, Bischoff, \& Wilde, 2011; Thiele, 1939; Yamané, Araki, \& Sada, 1981) have presented similar definitions of $\left(\eta_{\text {internal }}\right)$ and $\left(\eta_{\text {overall }}\right)$.

In this research, the use of $(\eta)$ in the calculation of an isothermal packed bed reactor with convection and reaction is discussed, and it is shown that the bed length $[L(\mathrm{~m})]$ and catalyst mass $\left[M_{p}(\mathrm{~kg})\right]$ in a packed bed can be calculated with or without $(\eta)$. A questionnaire was prepared to verify the students' level of difficulty in understanding two theoretical topics taught in the last two classes, in doing the requested calculations, as well as the similarity they found between using the calculation methods with the use of the effectiveness factor and without it. We also investigated how the students felt about the elimination of traditional monthly exams in Chemical Reactor Design.

\section{Packed Bed Reactor without Effectiveness Factor}

The reaction in a packed bed is assumed to take place in many particles, rather than in a single particle. $C_{A f}\left(\mathrm{~kg}-\mathrm{mol} / \mathrm{m}^{3}\right)$ is the bulk fluid-phase concentration of (A) at any point along the length of the packed bed (Fogler, 1992).

Various spherical particles are present in a catalytic reactor and are submerged in a fluid phase containing the mixture of reactant (A) and product (B). We assume that each catalyst particle is surrounded by a fluid in movement, through which component (A) has to move to reach the surface of the catalyst. On the catalyst's surface, the reaction $\mathrm{A} \rightarrow \mathrm{B}$ is thought to occur on the catalyst surface and the reaction product then diffuses back out through the mixture composed of reactants and products (Bird, Stewart, \& Lightfoot, 2002: pp. 551, 565).

Any radial variations in concentration are neglected and the packed bed is assumed to operate at a steady state. The mass balance for component (A) based on bulk concentration $\left(C_{A f}\right)$ is solved for the case in which the flow rate through the packed bed is very large, i.e., a plug flow model is adopted and the axial dispersion can be neglected (Fogler, 1992: p. 630; Froment, Bischoff, \& Wilde, 2011). A mass balance on (A) of a slice of thickness $(\mathrm{d} z)$, cross section $\left(\pi R_{b}^{2}\right)$ of the packed bed of volume $\mathrm{d} V_{b}=(\mathrm{d} z)\left(\pi R_{b}^{2}\right)$, where $\left(R_{b}\right)$ is the packed bed radius and $V_{\text {sup }}(\mathrm{m} / \mathrm{s})$ is the fluid superficial velocity, using a one-dimensional model and an isothermal packed bed reactor

$$
\begin{aligned}
v_{\text {sup }} \frac{\mathrm{d} C_{A f}}{\mathrm{~d} z} & =R_{A p(\mathrm{obs})} \frac{\text { Volume of all particles in cross section }\left(\mathrm{m}^{3}\right)}{\text { Volume of considered cross section }\left(\mathrm{m}^{3}\right)} \\
v_{\text {sup }} & =\frac{\text { Volumetric flow rate }\left(\mathrm{m}^{3} / \mathrm{s}\right)}{\text { Cross-sectional area of the bed }\left(\mathrm{m}^{2}\right)}=\frac{Q}{\pi R_{b}^{2}}
\end{aligned}
$$

Assuming $\left(V_{p}\right)$ as the volume of all particles in the considered cross section, the fluid volume $\left(V_{f}\right)$ in the same section, the total volume $V_{\text {total }}=V_{p}+V_{f}$ and the porosity of the bed $\varepsilon_{b}=V_{f} / V_{\text {total }}$, using Equation (1) results in

$\frac{\text { Volume of all particles in cross section }\left(\mathrm{m}^{3}\right)}{\text { Volume of considered cross section }\left(\mathrm{m}^{3}\right)}=\frac{V_{p}}{V_{p}+V_{f}}=\frac{V_{p}+V_{f}-V_{f}}{V_{p}+V_{f}}=\frac{V_{p}+V_{f}}{V_{p}+V_{f}}-\frac{V_{f}}{V_{p}+V_{f}}=1-\varepsilon_{b}$ 
Replacing Equation (3) into (1)

$$
v_{\text {sup }} \frac{\mathrm{d} C_{A f}}{\mathrm{~d} z}=\left(1-\varepsilon_{b}\right) R_{A p(\text { obs })}
$$

The flux $N_{A p}\left[\mathrm{~kg} \cdot \mathrm{mol} /\left(\mathrm{m}^{2} \cdot \mathrm{s}\right)\right]$ of the component (A) in a particle with external mass transfer coefficient $k_{m}\left[\mathrm{~m}^{3} /\left(\mathrm{m}^{2} \cdot \mathrm{s}\right)\right]$ and the concentration of (A) on the external catalyst surface $\left(C_{A R p}\right.$ ) for particle surface $r=R_{p}$ is

$$
N_{A p}\left(r=R_{p}\right)=k_{m}\left(C_{A R p}-C_{A f}\right)
$$

Multiplying the surface area $\left(A_{p}\right)$ of the sphere, and by dividing its volume $\left(V_{p}\right)$ by the flux $\left(N_{A p}\right)$, the observed reaction rate in a spherical particle is obtained

$$
R_{A(o b s)}=\frac{4 \pi R_{p}^{2}}{\frac{4}{3} \pi R_{p}^{3}} k_{m}\left(C_{A R p}-C_{A f}\right)=\left(3 / R_{p}\right) k_{m}\left(C_{A R p}-C_{A f}\right)
$$

Equation (5) and Equation (6) are valid for one catalyst particle. They were adapted for a packed bed reactor by multiplying the volume fraction occupied by all catalyst particles in the bed as a function of the bed porosity $\varepsilon_{b}$ (dimensionless). Specifically, multiplying $\left(1-\varepsilon_{b}\right)$ by the observed reaction rate in a particle $R_{A(\text { obs })}$ or using the parameter $a_{v}\left(\mathrm{~m}^{2} / \mathrm{m}^{3}\right)=\left(3 / R_{p}\right)\left(1-\varepsilon_{b}\right)$ the observed reaction rate in the bed $R_{A(\mathrm{obs} . \text { in bed })}$ with volume $\mathrm{d} V_{b}=\pi R_{b}^{2} \mathrm{~d} z$ is obtained. Inserting Equation (6) into Equation (4) gives

$$
v_{\text {sup }} \frac{\mathrm{d} C_{A f}}{\mathrm{~d} z}=\left(3 / R_{p}\right)\left(1-\varepsilon_{b}\right) k_{m}\left(C_{A R p}-C_{A f}\right)=a_{v} k_{m}\left(C_{A R p}-C_{A f}\right)
$$

$\left(C_{A R P}\right)$ is obtained from the solution of the mass balance of component (A) in an individual catalytic spherical particle with diffusion and reaction. $\left(C_{A R P}\right)$ is obtained and discussed a posteriori in Equation (29) in Section 3. Substituting $C_{A R p}=F_{1} C_{A f}$ from Equation (29) into Equation (7)

$$
\begin{gathered}
v_{\text {sup }} \frac{\mathrm{d} C_{A f}}{\mathrm{~d} z}=\left(3 / R_{p}\right)\left(1-{ }_{b}\right) k_{m}\left(F_{1} C_{A f}-C_{A f}\right)=a_{v} k_{m}\left(F_{1}-1\right) C_{A f} \\
F_{1}=\frac{1}{1-\left(1 / B i_{m}\right)\left(1-\phi_{1} \cosh \phi_{1} / \sinh \phi_{1}\right)} \\
\phi_{1}=\sqrt{k_{1}^{\prime \prime} \rho_{p} S_{g} R_{P}^{2} / D_{e f}} \\
B i_{m}=\frac{k_{m} R_{p}}{D_{e f}}=\frac{1 /\left(D_{e f} / R_{p}\right)}{1 / k_{m}}=\frac{\text { Internal diffusive resistance in the particle }}{\text { External mass transfer resistance in the fluid film }}
\end{gathered}
$$

where $F_{1}$ (dimensionless) is a parameter, $\phi_{1}$ (dimensionless) is the Thiele modulus, $k_{1}^{\prime \prime}$ $\left[\mathrm{m}^{3} /\left(\mathrm{m}^{2} \cdot \mathrm{s}\right)\right]$ is the kinetic coefficient of the superficial reaction rate, $\rho_{p}\left(\mathrm{~kg} / \mathrm{m}^{3}\right)$ is the particle density, $S_{g}\left(\mathrm{~m}^{2} / \mathrm{kg}\right)$ is the available catalytic surface per unit mass, and $B i_{m}$ (dimensionless) is the Biot number for mass transfer.

Integrating Equation (8) from $Z=0$ and $\left(C_{A 0}\right)$ to $Z=Z(\mathrm{~m})$ and $\left(C_{A f}\right)$ gives

$$
C_{A f}=C_{A f 0} \exp \left[-a_{v} k_{m}\left(1-F_{1}\right) z / v_{\text {sup }}\right]
$$

The length of the packed bed $(L)$ is obtained by reorganizing Equation (12) 


$$
L=v_{\text {sup }} \ln \left(C_{A f} / C_{A f 0}\right) /\left[a_{v} k_{m}\left(F_{1}-1\right)\right]
$$

The mass of catalyst particles $M_{p}(\mathrm{~kg})$ in a packed bed of volume $V_{b}=\pi R_{b}^{2} L$ is

$$
M_{p}=\left(1-\varepsilon_{b}\right) \rho_{p} \pi R_{b}^{2} L
$$

\section{Example of a Packed Bed Reactor without the Effectiveness Factor}

This section presents the solution performed by the students for an example of using the equations for a packed bed with reaction and convection but without effectiveness factor.

We solved Example (11-3), "Reducing nitrous oxides in a plant effluent", presented by Fogler (1992: pp. 631-634) and Example (12-4) presented by Fogler (2006: pp. 845848). Fogler proposes reducing the concentration of $\mathrm{NO}$ in the effluent stream from a plant through a packed bed of spherical porous carbonaceous solid pellets. A $2 \% \mathrm{NO}$ and $98 \%$ air mixture flows at a rate of $Q=1 \times 10^{-6} \mathrm{~m}^{3} / \mathrm{s}$ through a tube packed with a porous solid at a temperature of $1173 \mathrm{~K}$ and a pressure of $101.3 \mathrm{kPa}$. The reaction $\mathrm{NO}+$ $\mathrm{C} \rightarrow \mathrm{CO}+(1 / 2) \mathrm{N}_{2}$ is first order in $\mathrm{NO}$ and occurs in the pores inside the pellet, where $S_{g}=$ $530 \mathrm{~m}^{2} / \mathrm{g}$ and $k_{1}^{\prime \prime}=4.42 \times 10^{-10} \mathrm{~m}^{3} /\left(\mathrm{m}^{2} \cdot \mathrm{s}\right)$. At $1173 \mathrm{~K}$, the effective diffusivity is $D_{e f}=$ $1.82 \times 10^{-8} \mathrm{~m}^{2} / \mathrm{s}$ (Fogler, 2006: p. 845) and $k_{m}=6 \times 10^{-5} \mathrm{~m}^{3} /\left(\mathrm{m}^{2} \cdot \mathrm{s}\right)$. Other catalyst and packed bed properties are $\varepsilon_{b}=0.5, \rho_{p}=2.8 \times 10^{6} \mathrm{~g} / \mathrm{m}^{3}, \rho_{b}=1.4 \times 10^{6} \mathrm{~g} / \mathrm{m}^{3}, R_{p}=3 \times 10^{-3}$ $\mathrm{m}$ and $R_{b}=0.0254 \mathrm{~m}$.

To calculate the length of the packed bed reactor $(L)$ and weight of the porous solid in bed $\left(M_{p}\right)$, it is necessary to reduce the NO concentration to a level of $0.004 \%$, which is below the Environmental Protection Agency limit (Fogler, 2006).

Without the $\left(\eta_{\text {overall }}\right)$, using Equations (2), (3), (9), (10), (13) and (14), the parameter $\left(a_{v}\right)$ and the data presented by Fogler (2006: p. 845) $(L)$ and $\left(M_{p}\right)$ are obtained

$$
\begin{aligned}
& \phi_{1}=\sqrt{\frac{k_{1}^{\prime \prime}\left(\rho_{p} S_{g}\right) R_{P}^{2}}{D_{e f}}}=\sqrt{\frac{\left(4.42 \times 10^{-10} \mathrm{~m} / \mathrm{s}\right)\left(2.8 \times 10^{6} \mathrm{~g} / \mathrm{m}^{3}\right)\left(530 \mathrm{~m}^{2} / \mathrm{g}\right)\left(3 \times 10^{-3} \mathrm{~m}\right)^{2}}{1.82 \times 10^{-8} \mathrm{~m}^{2} / \mathrm{s}}}=18.01 \\
& B i_{m}=k_{m} R_{p} / D_{e f}=\left(6 \times 10^{-5} \mathrm{~m} / \mathrm{s}\right)\left(3 \times 10^{-3} \mathrm{~m}\right) /\left(1.82 \times 10^{-8} \mathrm{~m}^{2} / \mathrm{s}\right)=9.89 \\
& F_{1}=\frac{1}{1-\left(1 / B i_{m}\right)\left(1-\phi_{1} \cosh \phi_{1} / \sinh \phi_{1}\right)}=\frac{1}{1-(1 / 9.89)(1-18.01 \cosh 18.01 / \sinh 18.01)}=0.368 \\
& a_{v}=\left(1-\varepsilon_{b}\right)\left(3 / R_{p}\right)=(1-0.5)\left[3 /\left(3 \times 10^{-3} \mathrm{~m}\right)\right]=500 \mathrm{~m}^{2} / \mathrm{m}^{3} \\
& v_{\text {sup }}=Q /\left(\pi R_{b}^{2}\right)=\left(1 \times 10^{-6} \mathrm{~m}^{3} / \mathrm{s}\right) /\left[\pi(0.0254 \mathrm{~m})^{2}\right]=0.000493 \mathrm{~m} / \mathrm{s} \\
& L=\frac{v_{\text {sup }} \ln \left(C_{\text {Af }} / C_{\text {Af } 0}\right)}{a_{v} k_{m}\left(F_{1}-1\right)}=\frac{(0.000493 \mathrm{~m} / \mathrm{s}) \ln (0.004 / 2.0)}{\left(500 \mathrm{~m}^{2} / \mathrm{m}^{3}\right)\left(6 \times 10^{-5} \mathrm{~m} / \mathrm{s}\right)(0.368-1)}=0.162 \mathrm{~m} \\
& M_{p}=\left(1-\varepsilon_{b}\right) \rho_{p} \pi R_{b}^{2} L=(0.5)\left(2.8 \times 10^{6} \mathrm{~g} / \mathrm{m}^{3}\right) \pi(0.0254 \mathrm{~m})^{2}(0.162 \mathrm{~m})=456.8 \mathrm{~g}
\end{aligned}
$$

\section{Packed Bed Reactor with Effectiveness Factor}

In Section 3.1, a model for a catalytic particle in which a first-order reaction is consi- 
dered. In Section 3.2, an equation valid for one catalyst particle is adapted for a packed bed reactor by multiplying the volume fraction occupied by all catalyst particles in the packed bed, and in Section 3.3 an example of calculation using the effectiveness factor is presented.

\subsection{Diffusion and Reaction in a Single Spherical Catalytic Particle}

Let us now consider a model for a catalytic particle in which a first-order reaction is carried out. It is admitted that a fluid in movement surrounds each catalyst particle and component (A) has to move through the catalyst particles to reach the catalyst surface (Bird, Stewart, \& Lightfoot, 2002: p. 565).

The mass balance to describe the diffusion and chemical reaction $R_{A}\left[\mathrm{~kg} \cdot \mathrm{mol} /\left(\mathrm{m}^{3} \cdot \mathrm{s}\right)\right]$ within a single porous spherical particle with radius $\left(R_{p}\right),\left(C_{A p}\right)$ concentration in the catalyst and effective diffusivity of the component (A) in the particle $D_{e f}\left(\mathrm{~m}^{2} / \mathrm{s}\right)$ is

$$
\frac{1}{r^{2}} \frac{\mathrm{d}}{\mathrm{d} r}\left(D_{e f} r^{2} \frac{\mathrm{d} C_{A p}}{\mathrm{~d} r}\right)+R_{A}=0
$$

The situation where species (A) becomes, according to a first-order chemical reaction $R_{A}=-k_{1}^{\prime \prime} \rho_{p} S_{g} C_{A p}$, is considered and Equation (22) becomes

$$
\frac{1}{r^{2}} \frac{\mathrm{d}}{\mathrm{d} r}\left(D_{e f} r^{2} \frac{\mathrm{d} C_{A p}}{\mathrm{~d} r}\right)-k_{1}^{\prime \prime} \rho_{P} S_{g} C_{A p}=0
$$

Reordering this equation results in

$$
\frac{\mathrm{d}^{2} C_{A p}}{\mathrm{~d} r^{2}}+\left(\frac{2}{r}\right) \frac{\mathrm{d} C_{A p}}{\mathrm{~d} r}-\left(\frac{\phi_{1}}{R_{p}}\right)^{2} C_{A p}=0
$$

Naturally, the internal diffusive resistance, $1 /\left(D_{e f} / R_{p}^{2}\right)$ and internal resistance to chemical reaction, $1 / k_{1}^{\prime \prime}$, are included in the Thiele modulus $\left(\phi_{1}\right)$ in Equation (24). This equation is solved with a finite concentration of $C_{A p}$ at $r=0$ and a flux outside the surface of the particle at $r=R_{p}$

$$
\begin{gathered}
C_{A p} \text { is finite at } r \rightarrow 0 \\
N_{A p}\left(r=R_{p}\right)=-D_{e f} \frac{\mathrm{d} C_{A p}}{\mathrm{~d} r}=k_{m}\left(C_{A R p}-C_{A f}\right)
\end{gathered}
$$

This boundary condition is reordered

$$
-R_{p} \frac{\mathrm{d} C_{A p}}{\mathrm{~d} r}=B i_{m}\left(C_{A R p}-C_{A f}\right) \text { at } r=R_{p}
$$

It is obvious that the internal diffusive resistance $1 /\left(D_{e f} / R_{p}\right)$ and the external convective resistance $1 / k_{m}$ are included in the Biot number for mass transfer $\left(B i_{m}\right)$. The solution of Equation (24) using Equation (25) and Equation (26) is (Bird, Stewart, \& Lightfoot, 2002: p. 853, Equation (C.1.6a))

$$
C_{A p}=\left(\frac{R_{p}}{r}\right) \sinh \left(\phi_{1} \frac{r}{R_{p}}\right) C_{A f} /\left[\sinh \phi_{1}-\left(\frac{1}{B i_{m}}\right)\left(\sinh \phi_{1}-\phi_{1} \cosh \phi_{1}\right)\right]
$$


$C_{A p}=f\left(C_{A f}, r, R_{p}, D_{e f}, k_{m}, k_{1}^{\prime \prime}, \rho_{p}, S_{g}\right)$ includes the effect of the internal diffusional resistance, external mass transfer resistance and reaction rate resistance in active sites. If $r=R_{p}$ in Equation (28), the concentration of (A) on the external catalyst surface $\left(C_{A R P}\right)$ with parameter $\left(F_{1}\right)$ in Equation (9) is

$$
C_{A R p}\left(r=R_{p}\right)=\frac{\sinh \phi_{1} C_{A f}}{\left[\sinh \phi_{1}-\left(1 / B i_{m}\right)\left(\sinh \phi_{1}-\phi_{1} \cosh \phi_{1}\right)\right]}=F_{1} C_{A f}
$$

Substituting Equation (29) into (26) gives the flux on surface $\left(N_{A p}\right)$

$$
N_{A p}\left(r=R_{p}\right)=-k_{m}\left(1-F_{1}\right) C_{A f}
$$

The observed reaction rate in a catalyst particle $R_{A(\mathrm{obs})}$ is obtained from Equation (6). Replacing Equation (29) into (6)

$$
R_{A(\text { obs })}=\left(3 / R_{p}\right) k_{m}\left(C_{A R p}-C_{A f}\right)=-\left(3 / R_{p}\right) k_{m}\left(1-F_{1}\right) C_{A f}
$$

When the concentrations everywhere are $C_{A p}=C_{A f}$ in all of the active sites inside the particle, the reference reaction rate in the catalyst is

$$
R_{A(\text { reference })}=-k_{1}^{\prime \prime} \rho_{P} S_{g} C_{A f}
$$

Taking the ratio of the two last equations and using the $\left(\eta_{\text {overall }}\right)$ definition

$$
\eta_{\text {overall }}=\frac{R_{A(\text { obs })}}{R_{A(\text { ref })}}=\frac{R_{A(\text { obs })}}{-k_{1}^{\prime \prime} \rho_{P} S_{g} C_{A f}}=\frac{-\left(3 / R_{p}\right) k_{m}\left(1-F_{1}\right) C_{A f}}{-k_{1}^{\prime \prime} \rho_{P} S_{g} C_{A f}}
$$

Similarly to $\left(C_{A p}\right)$, the function $\eta_{\text {overall }}=f\left(C_{A f}, R_{p}, D_{e f}, k_{m}, k_{1}^{\prime \prime}, \rho_{p}, S_{g}\right)$ includes the effect of the internal diffusional resistance, the external mass transfer resistance and the reaction rate resistance.

$\left(\eta_{\text {overall }}\right)$ can be written in another form based on the diffusive flux $\left(-D_{e} \mathrm{~d} C_{A p} / \mathrm{d} r\right)$ on the external surface at $r=R_{p}$. The derivative of $C_{A p}$ in Equation (28), $\mathrm{d} C_{A p} / \mathrm{d} r$ gives the flux using Equation (26) or Equation (27) and $N_{A p}=-D_{e A} \mathrm{~d} C_{A p} / \mathrm{d} r$ at $r=R_{p}$, which, multiplied by the outside area $\left(A_{p}\right)$ per volume $\left(V_{p}\right)$ of spherical particle, results in

$$
R_{A(\text { obs })}\left(r=R_{p}\right)=\frac{-3 D_{e f}}{R_{p}^{2}}\left(\frac{\phi_{1} \cosh \phi_{1}}{\sinh \phi_{1}}-1\right) F_{1} C_{A f}
$$

The result of Equation (34) is equal to Equation (31). Substituting Equation (34) into (33), using $\left(\phi_{1}\right)$ and $\left(F_{1}\right)$, results in a general solution

$$
\eta_{\text {overall }}=\frac{-\left(3 D_{e f} / R_{p}^{2}\right)\left(\phi_{1} \cosh \phi_{1} / \sinh \phi_{1}-1\right) F_{1} C_{A f}}{-k_{1}^{\prime \prime} \rho_{P} S_{g} C_{A f}}=\frac{3 F_{1}\left(\phi_{1} \cosh \phi_{1} / \sinh \phi_{1}-1\right)}{\phi_{1}^{2}}
$$

Reordering Equation (35) gives the analytical equation of ( $\left.\eta_{\text {overall }}\right)$ for a first-order reaction and incorporates the influences of the resistances into the process in a spherical geometry

$$
\frac{1}{\eta_{\text {overall }}}=\frac{1}{\left(3 / \phi_{1}^{2}\right) B i_{m}}+\frac{1}{\left(3 / \phi_{1}^{2}\right)\left(\phi_{1} \cosh \phi_{1} / \sinh \phi_{1}-1\right)}
$$

Equation (36) is similar to that presented by Yamané, Araki, \& Sada (1981) if $K_{p}=1$. 
However, it includes $K_{p}$ (dimensionless), the equilibrium partition coefficient or distribution coefficient. The $\left(\eta_{\text {overall }}\right)$ incorporating $\left(K_{p}\right)$ provides a useful criterion for choosing and designing a suitable catalyst particle for a particular reaction (Yamané, Araki, \& Sada, 1981). If $B i_{m} \rightarrow \infty$ in Equation (36) the ( $\left.\eta_{\text {internal }}\right)$ results in a special solution. Fogler (1992: p. 632) presents Equation (11-32) for $\left(\eta_{\text {internal }}\right)$, which is equal to the equation presented by Yamané, Araki, \& Sada (1981) for $B i_{m} \rightarrow \infty, K_{p}=1$ and a first-order reaction rate. An equal equation is presented by Bird, Stewart, \& Lightfoot (2002: p. 566) and Froment, Bischoff, \& Wilde (2011: p. 196) for ( $\left.\eta_{\text {internal }}\right)$.

\subsection{Convection and Reaction in a Packed Bed Reactor with Effectiveness Factor}

Equation (4) is a general solution and is valid for one catalyst particle. Equation (4) can be adapted for a packed bed reactor by multiplying the volume fraction occupied by all catalyst particles in a packed bed, i.e., $\left(1-\varepsilon_{b}\right)$ by the actual observed reaction rate in a particle $R_{A(\mathrm{obs})}$. Substituting this parameter in Equation (1), using a one-dimensional model, an isothermal packed bed reactor and assuming that the packed bed operates at a steady state

$$
v_{\text {sup }} \frac{\mathrm{d} C_{A f}}{\mathrm{~d} z}=\left(1-\varepsilon_{b}\right) \eta_{\text {overall }}\left(-k_{1}^{\prime \prime} \rho_{P} S_{g} C_{A f}\right)=-\eta_{\text {overall }} k_{1}^{\prime \prime} S_{g} \rho_{b} C_{A f}
$$

Equation (37) is similar to Equation (11-69) from Fogler (1992: p. 630) and Equation (12-69) from Fogler (2006: p. 844) Integrating Equation (37) from $z=0$ and $C_{A f}=C_{A f 0}$ to $Z=L_{\text {overall }}$ and $C_{A f}$ give a concentration of $\left(C_{A f}\right)$ and the length of the packed bed based on $\left(\eta_{\text {overall }}\right)$ and $L_{\text {overall }}$

$$
\begin{gathered}
C_{A f}=C_{A f 0} \exp \left[-\eta_{\text {overall }}\left(1-\varepsilon_{b}\right) k_{1}^{\prime \prime} \rho_{P} S_{g}\left(1 / v_{\text {sup }}\right) L_{\text {overall }}\right] \\
L_{\text {overall }}=-v_{\text {sup }} \ln \left(C_{A f} / C_{A f 0}\right) /\left[\eta_{\text {overall }}\left(1-\varepsilon_{b}\right) k_{1}^{\prime \prime} \rho_{P} S_{g}\right]
\end{gathered}
$$

Equation (39) is similar to Equation (E11-3.2) in Fogler (1992: p. 630) and Equation (12-70) in Fogler (2006: p. 844).

The mass of the catalyst particles in the packed bed $\left(M_{p}\right)$ in volume $V_{b}=\pi R_{b}^{2} L_{\text {overall }}$ is:

$$
M_{p}=\left(1-\varepsilon_{b}\right) \rho_{p} \pi R_{b}^{2} L_{\text {overall }}
$$

\subsection{Example of a Packed Bed Reactor with Effectiveness Factor}

The parameters were calculated using Equations (35), (39) and (40), with $\phi_{1}=18.01$ and $F_{1}=0.368$, based on data from Fogler (2006)

$$
\begin{gathered}
\eta_{\text {overall }}=\frac{3 F_{1}\left(\phi_{1} \cosh \phi_{1} / \sinh \phi_{1}-1\right)}{\phi_{1}^{2}}=\frac{3(0.368)(18.01 \cosh 18.01 / \sinh 18.01-1)}{18.01^{2}}=0.0578 \\
L_{\text {overall }}=\frac{-v_{\text {sup }} \ln \left(C_{A f} / C_{A f 0}\right)}{\eta_{\text {overall }}\left(1-\varepsilon_{b}\right) k_{1}^{\prime \prime} \rho_{P} S_{g}}=\frac{-(0.000493 \mathrm{~m} / \mathrm{s}) \ln (0.004 / 2.0)}{0.0578(0.5)\left(4.42 \times 10^{-10} \mathrm{~m} / \mathrm{s}\right)\left(2.8 \times 10^{6} \mathrm{~g} / \mathrm{m}^{3}\right) 530 \mathrm{~m}^{2} / \mathrm{g}}=0.162 \mathrm{~m} \\
M_{p}=\left(1-\varepsilon_{b}\right) \rho_{p} \pi R_{b}^{2} L_{\text {overall }}=0.5\left(2.8 \times 10^{6} \mathrm{~g} / \mathrm{m}^{3}\right) \pi(0.0254 \mathrm{~m})^{2} 0.162 \mathrm{~m}=456.8 \mathrm{~g}
\end{gathered}
$$


The calculated values for the reactor length and mass of the catalyst are the same for both methods. The results presented in this work are similar to the values of the calculations performed by Fogler (2006) with a small difference resulting from simplification of the equation of $\left(\eta_{\text {overall }}\right)$.

The "mathematical trick" used in the present paper was the substitution of the concentration of component (A) on surface $\left(C_{A R p}\right)$ with $C_{A R P}=F_{1} C_{A f}$ from Equation (29). For example, in the flux in Equation (26) or Equation (27) the calculation of $(L)$ and $\left(M_{p}\right)$ can be completed without the necessity of using $\left(\eta_{\text {overall }}\right)$.

\section{Results and Discussion}

The model presented without the use of $\left(\eta_{\text {overall }}\right)$ was employed by reactor engineering students in two classes: one for a theoretical lecture by the professor and another for calculation by the students. The model without $\left(\eta_{\text {overall }}\right)$ was presented in a 50 -min class, and in another 50-min class, various groups of two students calculated the length of the reactor and the mass of the catalyst in the bed, which is presented in Section 2. In another class and in a similar way, the students calculated the model with $\left(\eta_{\text {overall }}\right)$, which is presented in Section 3. However, we are in the whole reactor design discipline replace traditional exams for activities in pairs, fully realized in the classroom.

We have used a methodology similar to that employed by Cartaxo, Silvino, \& Fernandes (2014) in the application of a questionnaire for students because privacy is a common concern for students when responding to surveys regarding pedagogical methods because they usually assume that their answers may affect their grades negatively. Thus, to promote student engagement, no identification data were requested from the respondents and appropriate care was taken during the questionnaire application (Cartaxo, Silvino, \& Fernandes, 2014).

Table 1 presents the questionnaire answered by the students. Out of the 23 students enrolled in the discipline in semester 2015.1, 19 were present and performed the calculations and 15 answered the questionnaire. Out of the 41 students enrolled in the discipline in semester 2016.1, 22 were present and performed the calculations and 20 answered the questionnaire. In an average of two semesters, $86 \%$ of the students reported feeling motivated by the varied class activities in comparison to traditional exams, $80 \%$ reported having little difficulty in understanding the two theoretical sections in the last two classes and $29 \%$ reported having no difficulty at all. Fifty-seven percent said that they did not have any difficulty in doing the calculations requested. Forty-three percent reported that the calculation methods with the use of the effectiveness factor and without its use were similar, and 51\% found the methods somewhat similar.

Stammitti (2013) concludes that the goal of updating the teaching and learning experience of chemical engineering students in the laboratory through computers was fulfilled by the introduction of spreadsheets. In the present article, our students created their own Excel spreadsheets for calculations with and without the effectiveness factor that were simpler than Stammitti's (2013). Writing Fortran programs was not necessary because the activities were simple. 
Table 1. Questionnaire on the two last classes and the activities performed in the discipline.

\begin{tabular}{ccc}
\hline \multirow{2}{*}{ Questions } & \multicolumn{2}{c}{ Number of responses per item } \\
\cline { 2 - 3 } & Semester 2015.1 & Semester 2016.1 \\
\hline
\end{tabular}

1) Did you have any difficulty understanding the two theoretical parts taught in the last two classes?

$\begin{array}{lcc}\text { ( ) None. } & 5 & 1 \\ \text { ( ) Little. } & 9 & 19 \\ \text { ( ) A lot. } & 1 & 0\end{array}$

2) Did you have any difficulty doing the calculations requested in the last two days of class activities?
( ) None.
( ) Little.
( ) A lot.

3) Did you find any similarity between the calculation methods with the use of the effectiveness factor and without it?

\section{( ) Yes.}

( ) Some

( ) None, they were quite different.
9

0

4) How do you prefer the evaluations in the Chemical Reactor Design discipline: four or five in-class activities or a single traditional exam?

( ) I prefer four or five in-class activities.

( ) I prefer a traditional exam.

14

0

1. Not answered

( ) Some other type of evaluation. Please, describe such other evaluation.

Only one student described another type of evaluation, which as follows: The in-class activities are quite productive; 4. Exam and activity. however, I suggest using a more detailed chemical reactor design for evaluation.

When necessary, we develop our own computer programs instead of using readily or commercially available simulators. One of the reasons is that the students will most likely retain their knowledge of Fortran programming even after some simulators are out of the market. Sometimes we compare our results to those of commercial simulators available in books and articles. Question (7) presented by Regalado-Méndez, CidRodríguez, \& Báez-González (2010) is related to the present article and is presented next. I understand all the concepts, with possible responses Yes and No. According to Regalado-Méndez, Cid-Rodríguez, \& Báez-González (2010), 80\% of the students understood the concepts. In the present article, $80 \%$ of the students reported having little 
difficulty in understanding the two theoretical sections in the last two classes.

Dahm \& Hesketh (2008) used specific student learning performance indicators from 2004 and 2005 such as indicator (1); the problem solution is usually correct and always reasonable, with values of $4=$ best and $1=$ worst. In the results presented by Dahm \& Hesketh (2008) from the spring of 2004, the students obtained a mean of 3.0, while in the spring of 2005, 12 students obtained a mean of 4.0. The 2004 class had some instances of students giving physically unrealistic answers such as temperature increases from endothermic reactions. Such errors were non-existent in 2005. In the present paper, 35 students performed the activity without the effectiveness factor and 34 obtained correct answers; when they used the effectiveness factor, all the answers were correct. Student feedback regarding the homogeneous kinetics laboratory module has been generally very positive (Ganley, 2015). Student attitudes and responses toward the module and its delivery indicated greater student satisfaction because the experimental hardware and the instructional documentation were each successively refined over the three semesters that the experiment has been in use.

The students used the two methodologies developed in class and considered the results that were obtained to be natural and positive for their training in chemical engineering. Student feedback regarding the calculations and studies performed in the computer laboratory were generally very positive.

\section{Conclusions}

This article describes two methods of calculation of a packed bed reactor involving reaction diffusion and convection concepts. Classroom analysis of a packed bed reactor with and without the use of the effectiveness factor $(\eta)$ is discussed. The use of $(\eta)$ in the calculation of an isothermal packed bed reactor with convection and first-order reaction rate is analyzed.

An analytical model has been developed with and without $(\eta)$. The model without $(\eta)$ was presented in a 50-min lecture and later used in a 50-min computational laboratory session with various pairs of students to calculate the length and catalyst mass in a packed bed reactor. In another class, the students calculated the model using $(\eta)$.

A questionnaire was prepared to verify the students' levels of difficulty in understanding the two theoretical topics taught in the last two classes, in doing the requested calculations, as well as the similarity they found between the calculation methods with the use of the effectiveness factor and without it. However, when consulted about their satisfaction with the elimination of traditional exams in Chemical Reactor Design, in an average of two semesters, $86 \%$ of the students preferred various class group activities in comparison to traditional exams, $80 \%$ reported that they had little difficulty in understanding the two theoretical sections in the last two classes, 57\% stated that they did not have any difficulty in doing the requested calculations and $51 \%$ reported that the calculation methods with the use of $(\eta)$ and without its use were somewhat similar.

The calculation results obtained with or without $(\eta)$ were identical; i.e., $(\eta)$ can be used but it is not mandatory. The analysis presented in this research provides motiva- 
tion beyond the simplified problems solved in textbooks about the use or lack thereof of $(\eta)$. In future research, we will present a discussion on the need or lack thereof to employ $(\eta)$. Additionally, future research will discuss some advantages, disadvantages and relevant aspects of the calculation of concentration, flow and $(\eta)$.

\section{References}

Bird, R. B., Stewart, W. E., \& Lightfoot, E. (2002). Transport Phenomena. New York: Wiley.

Cartaxo, S. J. M., Silvino, P. F. G., \& Fernandes, F. A. N. (2014). Transient Analysis of Shell-andTube Heat Exchangers Using an Educational Software. Education for Chemical Engineering, 9, e77-e84. http://dx.doi.org/10.1016/j.ece.2014.05.001

Dahm, K., \& Hesketh, R. (2008). Two Experiments for the Introductory Chemical Reaction Engineering Course. Education for Chemical Engineering, 3, e1-e5. http://dx.doi.org/10.1016/j.ece.2007.07.001

Fogler, H. S. (1992). Elements of Chemical Reaction Engineering (2cd ed.). London: Prentice-Hall.

Fogler, H. S. (2006). Elements of Chemical Reaction Engineering (4th ed.). Boston: Prentice-Hall.

Froment, G. F., Bischoff, K. B., \& Wilde, J. (2011). Chemical Reactor Analysis and Design (3rd ed.). New York: Wiley.

Ganley, J. C. (2015). A Homogeneous Chemical Reactor Analysis and Design Laboratory: The Reaction Kinetics of Dye and Bleach. Education for Chemical Engineering, 12, 20-26. http://dx.doi.org/10.1016/j.ece.2015.06.005

Glassey, J., Novakovic, K., \& Parr, M. (2013). Enquiry Based Learning in Chemical Engineering Curriculum Supported by Computer Aided Delivery. Education for Chemical Engineering, 8, e87-e93. http://dx.doi.org/10.1016/j.ece.2013.06.003

Luzi, C. D., Bressa, S. P., Mazza, G. D., \& Barreto, G. F. (2014). A Supporting Formulation for Introducing Gas-Liquid Reactions. Education for Chemical Engineering, 9, e50-e66. http://dx.doi.org/10.1016/j.ece.2014.04.001

Mahecha-Botero, A., Reaume, S., Grace, J. R., \& Ellis, N. (2011). Independent Research as a Teaching Tool in Graduate Chemical Reaction Engineering. Case Study: Modelling Isomerization of Unsaturated Fatty Acids with Catalyst Deactivation. Education for Chemical Engineering, 6, e1-e9. http://dx.doi.org/10.1016/j.ece.2010.09.002

Regalado-Méndez, A., Cid-Rodríguez, M. R. P., \& Báez-González, J. G. (2010). Problem Based Learning (PBL): Analysis of Continuous Stirred Tank Chemical Reactors with a Process Control Approach. International Journal of Software Engineering \& Applications, 1, 54-73.

Stammitti, A. (2013). Spreadsheets for Assisting Transport Phenomena Laboratory Experiences. Education for Chemical Engineering, 8, e58-e71. http://dx.doi.org/10.1016/j.ece.2013.02.005

Thiele, E. W. (1939). Relation between Catalytic Activity and Size of Particle. Industrial and Engineering Chemistry, 31, 916-920. http://dx.doi.org/10.1021/ie50355a027

Yamané, T., Araki, S., \& Sada, E. (1981). Overall Effectiveness Factor Incorporating Partition Coefficient of Gel-Immobilized Enzyme Pellet. Journal of Fermentation Technology, 59, 367374. 
Submit or recommend next manuscript to SCIRP and we will provide best service for you:

Accepting pre-submission inquiries through Email, Facebook, LinkedIn, Twitter, etc. A wide selection of journals (inclusive of 9 subjects, more than 200 journals)

Providing 24-hour high-quality service

User-friendly online submission system

Fair and swift peer-review system

Efficient typesetting and proofreading procedure

Display of the result of downloads and visits, as well as the number of cited articles

Maximum dissemination of your research work

Submit your manuscript at: http://papersubmission.scirp.org/ 